\title{
Retraction
}

\section{Retracted: An Automatic Web Service Composition Framework Using QoS-Based Web Service Ranking Algorithm}

\author{
The Scientific World Journal \\ Received 20 April 2016; Accepted 20 April 2016 \\ Copyright (C) 2016 The Scientific World Journal. This is an open access article distributed under the Creative Commons Attribution \\ License, which permits unrestricted use, distribution, and reproduction in any medium, provided the original work is properly \\ cited.
}

The Scientific World Journal has retracted the article titled "An Automatic Web Service Composition Framework Using QoS-Based Web Service Ranking Algorithm” [1]. After conducting a thorough investigation, we have strong reason to believe that the peer review process was compromised.

This article was originally submitted to a Special Issue titled "Recent Advances in Metaheuristics and Its Hybrids." In late 2015, Dr. Xavier Delorme, the lead guest editor on the Special Issue, alerted us that his identity had been compromised. After further investigation, we discovered that several peer review reports in this issue had been submitted from similarly compromised email accounts.

We are retracting the articles in keeping with the "COPE statement on inappropriate manipulation of the peer review process." There is no evidence that any of the authors or editors, including Dr. Delorme, were aware of this misconduct.

\section{References}

[1] D. Mallayya, B. Ramachandran, and S. Viswanathan, "An automatic web service composition framework using QoS-based web service ranking algorithm," The Scientific World Journal, vol. 2015, Article ID 207174, 14 pages, 2015. 